\title{
Purification and Biochemical Characteristics of Occlusion Body of Penaeus monodon-Type Baculovirus (MBV)
}

\author{
P.-S. Chang, Y.-C. Wang, C.-F. Lo, G.-H. Kou \\ and S.-N. Chen \\ Department of Zoology, National Taiwan University, \\ Taipei, Taiwan, ROC.
}

(Received November 18, 1991)

\begin{abstract}
In the present study, occlusion bodies (OBs) of Penaeus monodon-type baculovirus (MBV) were collected from infected juvenile $P$. monodon and then the OBs were purified by centrifugation for $30 \mathrm{~min}$ at a speed of $100,000 \times \mathrm{g}$ using $35-65 \%(\mathrm{w} / \mathrm{w})$ sucrose gradient. Analysis of polypeptides of MBV occlusion bodies showed 12 polypeptides in SDS-PAGE gel. It was also concluded that the major band with molecular mass of $62 \mathrm{k}$ dalton may be derived from protein of polyhedrin.
\end{abstract}

In the past decade intensive shrimp aquaculture has become one of the most powerful agriculture industries in the world. However, many diseases have accompanied by high culture density, and some diseases have resulted in mass mortalities of cultured shrimp. Therefore investigations on shrimp diseases and seeking for solutions are urgently needed. Amongst various shrimp pathogens investigated, viruses are considered to be important due to the wide-spreading and high infection rate (Lightner, 1983). To date, six viruses including Baculovirus penaei (BP) (Couch, 1974), baculoviral midgut gland necrosis (BMNV) (Sano et al., 1981), Penaeus monodon-type baculvirus (MBV) (Lightner and Redman, 1981), the parvovirus infectious hypodermal and hematopoietic necrosis virus (IHNV) (Lightner et al., 1983); hepatopancreatic parvo-like virus (HPV) (Lightner and Redman, 1985), and a reo-like virus of the hepatopancreas found in Penaeus japonicus (Tsing and Bonami, 1984)* have been reported in penaeid shrimp and may cause an unexpected mortality for various species of shrimp.

$\mathrm{MBV}$, belonging to a member of the family Baculoviridae, is pathogenic to several species of

* Tsing, A. and J. R. Bonami (1984): A new virus disease in the shrimp Penaeus japonicus. Premier Colloque International de Pathologie en Aquaculture Marine, Laboratoire de Pathologie Comparee, Montpellier Cedex, France, 11-14. Sept., 1984. shrimp such as $P$. monodon, $P$. penicillatus and Metapenaeus ensis (Chen et al., 1987a, b; Doubrovsky et al., 1988). Cytopathology and ultrastructure have been studied extensively in detail by Chen et al. (1989b). Investigations of MBV infection in cultured shrimp in Taiwan and in other localities of Asia have revealed serious epizootics in these culture systems (Chen et al., 1989a, 1990).

In recent years, one of the most serious problems of shrimp culture has been focused on viral infections. Although no curative techniques have been initiated for viral diseases, development of preventive measures and rapid diagnostic tools for the infection are of current importance to shrimp aquaculture industry. The present work attempts to purify and characterize occlusion bodies of MBV from the infected juvenile $P$. monodon in order to realize some general properties of the virus. This may provide important information on the development on both serological and DNAbased diagnostic approaches.

\section{Materials and Methods}

\section{Collection of MBV-Infected Shrimp}

For virus purification, virus-infected juvenile shrimp ( $P$. monodon) were collected from diseased shrimp ponds in Kaoshiung, southern Taiwan. The shrimp were dissected using fine forceps and hepatopancreata were collected in a room temperature and frozen immediately in $-20^{\circ} \mathrm{C}$ until 
experimental uses.

\section{Isolation of Viral Occlusion Bodies}

The collected hepatopancreata were homogenized in $0.02 \mathrm{M}$ Tris buffer ( $\mathrm{pH} 7.5$ ) in a homogenizer for $3 \mathrm{~min}$ at a speed of $10,000 \mathrm{rpm}$. The homogenate was filtered through $400 \mu \mathrm{m}$ Nytexmeshed sieves and the filtrate was centrifuged at $500 \times \mathrm{g}$ for $15 \mathrm{~min}$ at $4^{\circ} \mathrm{C}$. The supernatant was discarded and the pellet was then resuspended in a solution containing $0.02 \mathrm{M}$ Tris buffer $(\mathrm{pH} 7.5)$ : $n$-Butanol: $n$-Hexane at a ratio of $10: 4: 1$. The suspension was thoroughly stirred, then centrifuged for $20 \mathrm{~min}$ at $2000 \times \mathrm{g}$. The supernatant was poured off and the pellets were resuspended in $0.02 \mathrm{M}$ Tris for purification by sucrose density gradient centrifugation as described below.

The suspension was layered onto a $35-65 \%$ $(\mathrm{w} / \mathrm{w})$ sucrose gradient and centrifuged for $30 \mathrm{~min}$ at a speed of $100,000 \times g$. Fractions from the sucrose gradient were collected with a needle at the top, diluted three fold with $0.02 \mathrm{M}$ Tris ( $\mathrm{pH}$ 7.5 ) and centrifuged for $20 \mathrm{~min}$ at $1000 \times \mathrm{g}$. The pellet was resuspended in Tris-EDTA buffer (10 mM Tris, $1 \mathrm{~mm}$ EDTA, pH 7.5). The purity of the occulusion bodies were checked under a light microscope at a magnification of $100 \times$ or
$200 \times$. The polypeptide profiles of occlusion bodies were performed by $10 \%$ SDS polyacrylamide gel electrophoresis.

\section{Results and Discussion}

\section{Purification of MBV Occlusion Bodies}

After sucrose gradient centrifugation, a sharp band was formed (Fig. 1). Observation for the fraction using a phase contrast microscope revealed that elliptical shaped MBV occlusion bodies (Figs. 2 and 3) were present in the bandcontaining zone, and no shrimp debris was observed.

The use of organic solvents was necessary to remove lipids and tissue debris of the hepatopancreata prior to sucrose gradient centrifugation. Ultrastructural observations showed that organic solvent-treated occlusion bodies revealed a disrupted viral morphology, and the particles appeared to be denatured mostly, with incomplete nucleocapsids, only a few virions maintained an intact DNA (Fig. 4). These morphological changes may be due, in part, to the effect of organic solvents, DNase and storage temperature. Therefore further investigations are needed to obtain a large quantity of viral DNA.

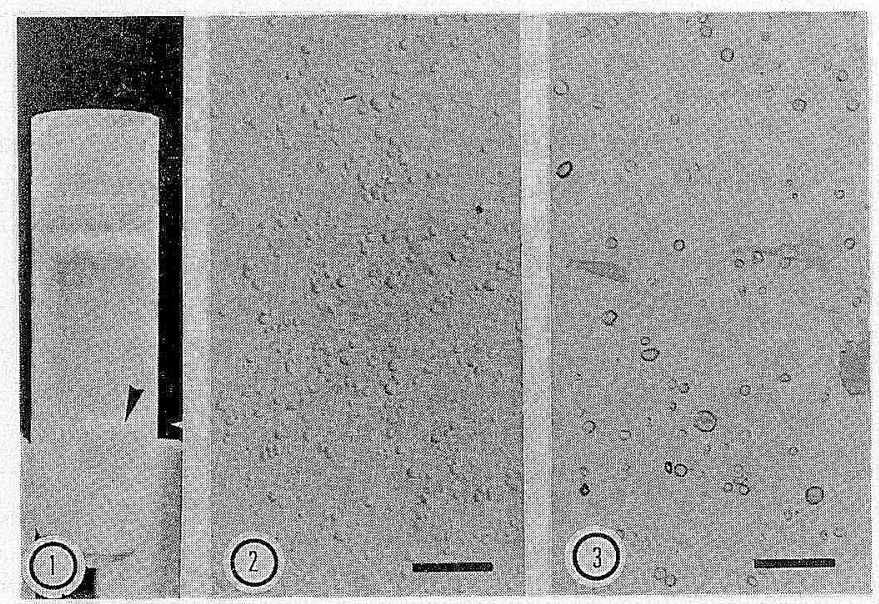

Fig. 1. Banding of Penaeus monodon-type baculovirus (MBV) occlusion bodies in suerose gradient $(35 \%-65 \%)$ (arrow).

Fig. 2. Purified occlusion bodies of Penaeus mondon-type baculovirus (MBV), observed under phase contrast microscopy, $\mathrm{Bar}=50 \mu \mathrm{m}$.

Fig. 3. Purified occlusion bodies of Penaeus monodon-type baculovirus (MBV) having elliptical shape and stained with eosin. Eosin $\left(0.1 \%\right.$ in $\left.\mathrm{H}_{2} \mathrm{O}\right)$ stain. $\mathrm{Bar}=25 \mu \mathrm{m}$. 


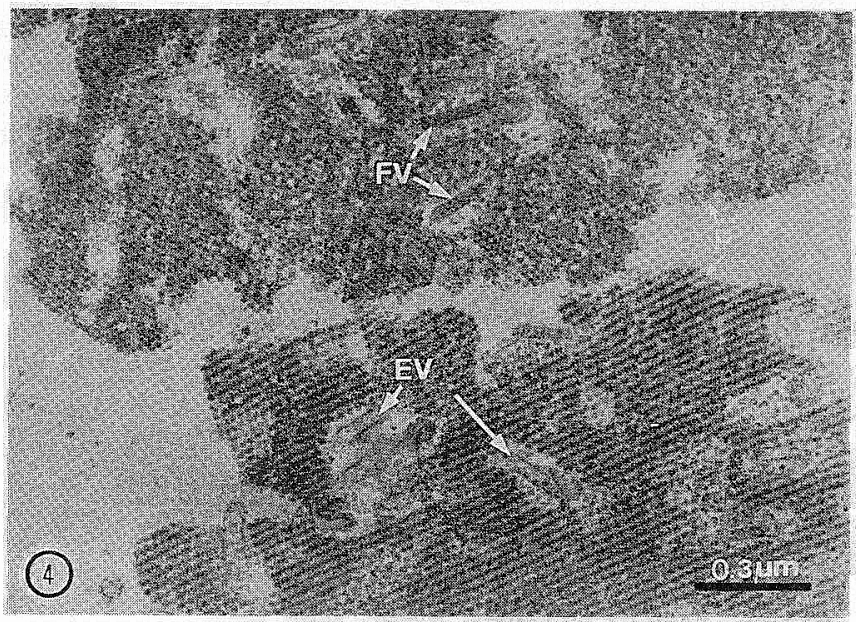

Fig. 4. Purified ocelusion bodies of Penaeus monodon-type baculovirus (MBV) detected by transmission electron microscopy.

$P$, polyhedrin; EV, empty virions, without DNA; FV, virions, filled with DNA.

Experiment performed on the storage of purified OBs showed that OBs stored in PBS at $-20^{\circ} \mathrm{C}$ dissolved after a period of time (longer than 1 month), while those stored in Tris buffer remained stable. However, Summers (1977) reported that Baculovirus penaei (BP) OBs were destroyed by Tris buffer. During the course of experiment, it was found that in order to minimize the effects from organic solvents it is important to purify OBs as quickly as possible. OBs of MBV appeared to be more stable at $\mathrm{pH} 7.5$ than in stronger alkaline or acidic solution, and were destroyed in weak acid solution at $\mathrm{pH}$ level below 6 .

\section{Polypeptides of MBV Occlusion Bodies}

Results of analysis on SDS-PAGE electrophoresis showed a total of 12 polypeptides present in MBV occulsion bodies. A major band of molecular mass $62 \mathrm{k}$ daltons, and 11 minor proteins of $160,125,60,55,50,45,40,34,32,31$ and $27 \mathrm{k}$ daltons were visualized using Coomassie Brilliant Blue R gels (Fig. 5). Results obtained from Western blot analysis using rabbit antiserum against purified $\mathrm{OBs}$ revealed that homogenate derived from MBV infected hepatopancreata gave a positive reaction at the position of $62 \mathrm{k}$ daltons. In contrast, no precipitation lines were observed when homogenate from MBV noninfected hepatopancreata was used (Fig. 6). These results may suggest that polyhedrin protein of
MBV apparently comprises the major band, and viral polypeptides should be included in the minor bands.

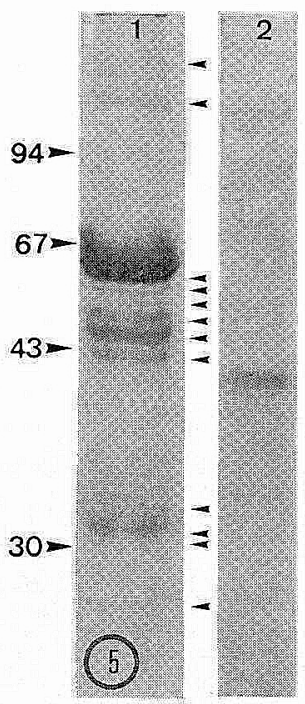

Fig. 5. One dimetnsion SDS-PAGE analysis of proteins fro homogenate of Penaeus monodon and extraction of occlusion bodies of Penaeus monodon-type baculovirus (MBV). Coomassie Brilliant Blue R (CBR) stain.

Lane 1, extract of MBV occlusion bodies; Lane 2, homogenate of MBV un-infected hepatopancreata. Positions of molecular size markers and the 12 polypeptides are indieated in $\mathrm{kDa}$ by arrow heads on the left and right side of Lane 1 , respectively. 


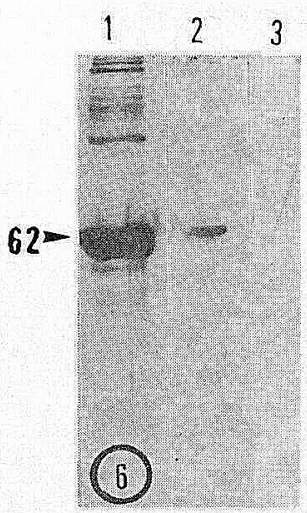

Fig. 6. Western blot analysis of extraction from Penaeus monodon-type baculovirus (MBV) occlusion bodies and homogenate from MBV infected and MBV un-infected hepatopancreata of $P$. monodon using antiserum against MBV occlusion bodies.

Lane 1, purified MBV OBs; Lane 2, homogenate from MBV infected hepatopancreata; Lane 3, homogenate from MBV un-infected hepatopancreata.

In comparison, the molecular size of polyhedrin of MBV appears to be slightly larger than that of BP (53 kDa; Summers, 1977), and about twice as large as polyhedrins of the insect baculoviruses (28 $38 \mathrm{kDa}$; McCarthy and Liu, 1976; Brown et al., 1979; Maskos and Miltenburger, 1981).

\section{Acknowledgments}

This work was supported by grants from National Science Council (Grant No. NSC 790211-B002-11 and 80-0209-B002-01) of Taiwan, Republic of China, and partially by the grant from joint project of Council of Agriculture and USDA (Grant No. FGTA-III, TW-AES-13).

\section{References}

Brown, M., A. M. Crawford and P. Faulkner (1979): Genetic analysis of a baculovirus Autographa californica nuclear polyhedrosis virus I. Isolation of temperature-sensitive mutants and assortment into complementation groups. J. Virol., 31, 190 198.

Chen, S.-N., P.-S. Chang and G.H-Kou (1989a): Observation on pathogenicity and epizootiology of Penaeus monodon baculovirus (MBV) in cultured shrimp in Taiwan. Fish Pathol., 24, 189-195.

Chen, S.-N., P.-S. Chang and G.-H. Kou (1989b): Studies on virogenesis and pathology of Penaeus monodon baculovirus (MBV) in the giant tiger prawn (Penaeus monodon) and the red tail prawn (Penaeus penicillatus). Fish Pathol., 24, 89-100.

Chen, S.-N. P.-S. Chang and G.-H. Kou (1990): Investigation of viral infection in cultured giant tiger prawn (Penaeus monodon) in Asia. Proc. ROCJapan Symp. Fish Dis. (ed. by G.-H. Kou, H. Wakabayashi, I.-C. Liao, S.-N. Chen and C.-F. Lo). National Science Council, Taipei, Taiwan. pp. 166171.

Couch, J. A. (1974): An enzootic nuclear polyhedrosis virus of pink shrimp: Utrastructure, prevalence, and enhancement. $J$. Invertebr. Pathol, 24, 311331.

Doubrovsky, A., J. L. Paynter, S. K. Sambhi, J. G. Atherton and R. J. G. Lester (1988): Observations on the ultrastructure of baculovirus in Australian Penaeus monodon and Penaeus merguiensis. Aust.J. Mar. Freshwater Res., 39, 743-749.

Lightner, D. V. (1983): Diseases of cultured penaeid shrimp. In "Mariculture" (ed. by J. P. McVey). CRC press, Boca Raton, Florida, pp. 289-320.

Lightner, D. V. and R. M. Redman (1981): A baculovirus-caused disease of the penaeid shrimp, Penaeus monodon. J. Invertebr. Pathol, 38, 299302.

Lightner, D. V. and R. M. Redman (1985): A parvolike virus disease of penaeid shrimp. $J$. Invertebr. Pathol., 45, 47-53.

Lightner, D. V., R. M. Redman and T. A. Bell (1983): Infectious hypodermal and hematopoietic necrosis, a newly recognized virus disease of penaeid shrimp. J. Invertebr. Pathol., 42, 62-70.

Maskos, C. B. and H. G. Miltenburger (1981): SDSPAGE comparative studies on the polyhedral and viral polypeptides of the nuclear polyhedrosis viruses of Mamestra brassicae, Autographa californica, and Lymantria dispar. J. Invertebr. Pathol., 36, 174180.

McCarthy, W. J. and S.-Y. Liu (1976): Electrophoretic and serological-characterization of Porthetric dispar polyhedron protein. J. Invertebr. Pathol., 28, 5765.

Sano, T., T. Nishimura, K. Oguma, K. Momoyama and N. Takeno, (1981): Baculovirus infection of cultured Kuruma shrimp Penaeus japonicus in Japan. Fish Pathol., 15, 185-191.

Summers, M. D. 1977. Characterization of shrimp baculovirus. U.S. Environmental Protection Agency Report (Ecological Research Series). No. EPA$600 / 3-77-130$. 